\title{
Multiple Renal Arteries with an Ascending Upward Renal Vein of the Right Kidney: a Case Report
}

\author{
Al-Shibli SM \\ Department of Basic Medical Sciences, Kulliyyah of Medicine, International Islamic University Malaysia, Kuantan, \\ Malaysia
}

\begin{abstract}
As it is known; the majority of the human subjects has two renal arteries arising from the abdominal aorta; each will supply one kidney but in $30 \%$ of individuals, certain variations can be found. Accessory renal arteries constitute the most common and clinically important of these variations. For our case report, we are presenting one of these different variations that can be found in the blood supply of the kidneys. During dissecting the abdomen of an approximately 65 years-old male cadaver, multiple variations were found. There were double right renal arteries with prehilar branching of the upper renal artery. We found also that the right renal vein ascended upwards obliquely before ending in the lateral aspect of the inferior vena cava. Variation in the renal vessels is relatively common, especially multiple renal arteries, and can go smoothly without any abnormalities with the function of the kidney, but in some situations like renal transplantations, vascular reconstructions, and various surgical and radiological diagnostic techniques, the study of the anatomy of these variations is of crucial importance to decrease the patient morbidity during surgical procedures.
\end{abstract}

KEYWORDS: Renal artery, renal vein, anatomical variation.

\section{INTRODUCTION}

In the majority of the human subjects, each kidney is supplied by one renal artery arising from the abdominal aorta, but in approximately $30 \%$ of individuals, more than one artery can be present. ${ }^{1}$

Renal arteries are usually 4-6 cm in length and 5-6 mm in diameter. They typically arise from the aorta at the level of L1-L2 intervertebral disc space below the origin of the superior mesenteric artery (SMA), and tend to course through the anterior portion of the renal pelvis. Each renal artery gives the inferior adrenal artery. ${ }^{2}$ The main renal artery then continues before dividing into four anterior branches at the renal hilum into the apical, upper, middle, and lower anterior segmental arteries. Renal veins course anterior to the renal arteries. The left renal vein normally courses between the SMA and aorta before draining into the medial aspect of the inferior vena cava (IVC), whereas the

Corresponding author:

Saad M. Al-Shibli MBChB, MRCSI

BMS Department, Kulliyyah of Medicine, International Islamic University Malaysia, Kuantan, Malaysia

Email: salshibli2004@yahoo.com

Phone No: 017-980 3382 right drains into the lateral aspect of the IVC. ${ }^{3}$ Accessory renal arteries constitute the most common and clinically important renal arterial variations and can be seen in up to one-third of the normal population. Accessory arteries usually arise from the aorta or iliac arteries at any level between T11 and L4. Typically, the accessory renal artery will reach the renal hilum to perfuse the upper or lower renal poles. ${ }^{4}$ Prehilar branching is another common variant that can be readily detected with $3 \mathrm{D}$ imaging. This variant is particularly important for the preoperative mapping of the renal transplant donors. Theoretically, it is the branching of the main renal arteries into segmental branches at a more proximal level than the renal hilum. ${ }^{5}$ Variations of the renal veins, and IVC occur infrequently, but if they remain unidentified in potential surgical candidates, this may increase surgical morbidity during operations, therefore, it is necessary to evaluate the renal veins and caval anatomy correctly. ${ }^{6}$

\section{CASE REPORT}

In the dissecting hall of Kulliyyah of Medicine, International Islamic University Malaysia (IIUM) and during dissecting the abdomen of an approximately 65 years-old male cadaver, we observed variations in the vascular architecture of the renal system; in the right renal artery and vein. There were double right renal arteries taking their origins from the aorta directly each with a length of $7.5 \mathrm{~cm}$. We found also a prehilar 


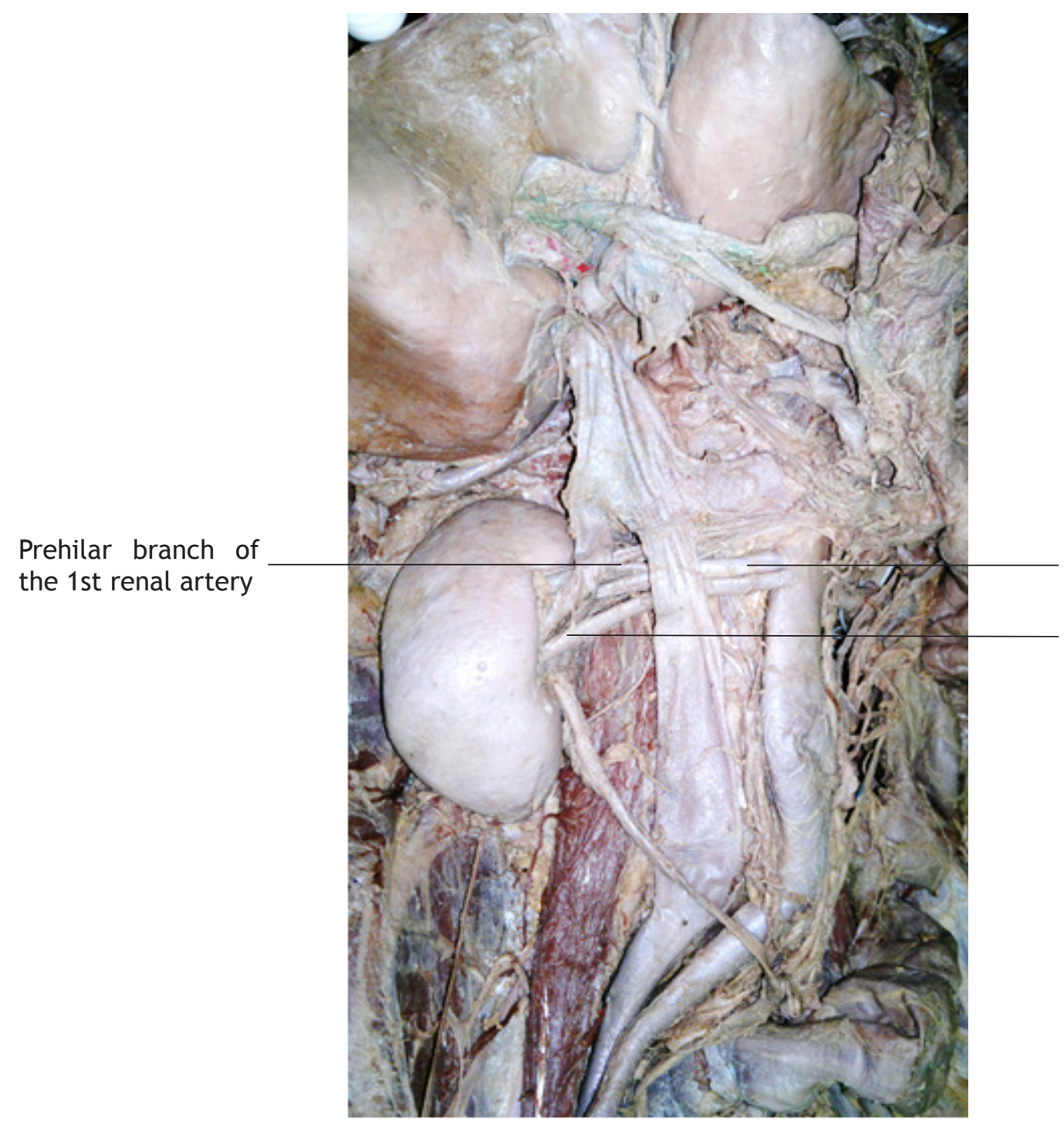

1st renal artery

2nd renal artery

Figure 1. Dissection of abdomen showing the right renal vasculature 


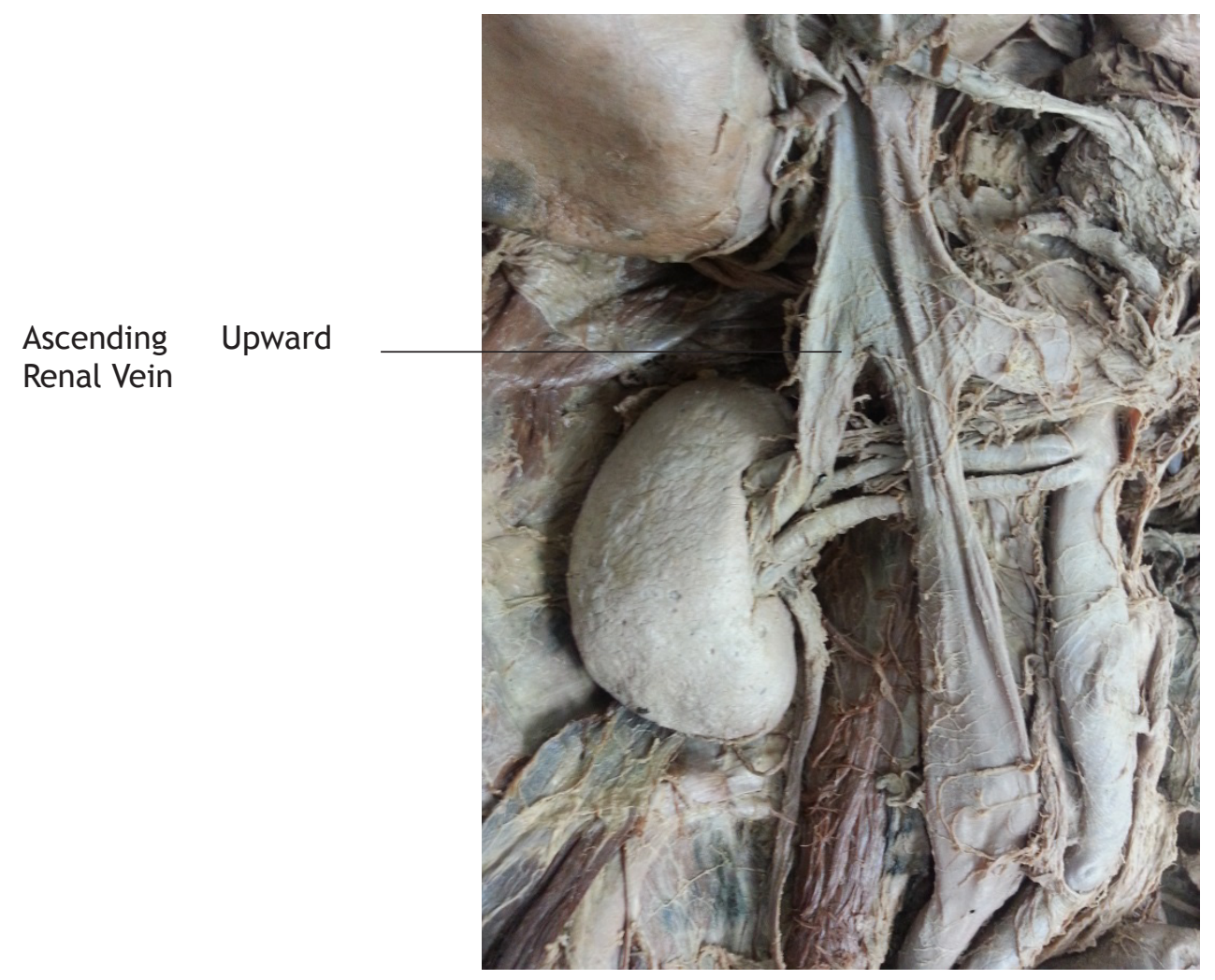

Figure 2. Dissection of abdomen showing variation in renal vasculature

\section{DISCUSSION}

Each kidney is supplied by one renal artery arising from the abdominal aorta, but in approximately $30 \%$ of individuals, more than one artery can be present. ${ }^{1}$ Renal veins lie anterior to the corresponding renal arteries and join with the inferior vena cava at close to ninety degree angles. They begin at the hilum of the kidney where three to six tributaries unite.

The left renal vein is longer than the right and takes on the left inferior phrenic vein, left suprarenal vein, left gonadal vein, and left second lumbar vein. This is unlike the right vein, which drain right into the inferior vena cava.

The left renal vein normally courses between the superior mesenteric artery and aorta before draining into the medial aspect of the IVC with an average length of $2.4 \pm 0.7 \mathrm{~cm},{ }^{9}$ whereas the right drains into the lateral aspect of the IVC. ${ }^{3}$

Variation of the renal vessels had been reported by many authors; Satheesha observed variation in the origin and course of the renal artery. The right renal artery took its origin from the aorta as its ventral branch, and then it descended downwards and to the right in front of the inferior vena cava and then entered the hilum of the right kidney. As the right renal artery passed in front of the inferior vena cava, it gave rise to the right ovarian artery. ${ }^{7}$ Turan Pestemalci noticed bilateral triple renal arteries. ${ }^{8}$ In our case, we found that there are double right renal arteries taking their origins from the aorta directly, with a prehilar branching of the upper renal artery which normally should be at the hilum of the kidney, then entered the hilum of the right kidney. On the other hand, we found that the right renal vein ascended upwards obliquely before ending in the lateral aspect of the inferior vena cava rather than in its orthtopic position, which is usually horizontal.

Accessory renal arteries constitute the most common and clinically important renal arterial variations and can be seen in up to one-third of the normal population. Accessory arteries usually arise from the aorta or iliac arteries at any level between T11 and L4. ${ }^{4}$

The most important significance of this abnormality is in laparoscopic surgery and in partial nephrectomy due to the difficulties in ligating or clamping the accessory artery which may lead to disastrous complications, mainly severe bleeding. ${ }^{10}$

The knowledge of variations of renal vessels is important for surgeons doing kidney transplants and 
to the radiologists. Variations of the renal veins and IVC occur infrequently, but if they remain unidentified in potential surgery candidates, this may increase surgical morbidity during operations; therefore, it is necessary to evaluate renal vein's anatomy correctly. ${ }^{6}$

\section{CONCLUSION}

Variation in the renal vessels is relatively common, especially multiple renal arteries, and can go smoothly without any abnormalities with the function of the kidney, but in some situations like renal transplantations, vascular reconstructions, and various surgical and radiological techniques, the study of the anatomy of these variations is of crucial importance.

\section{REFERENCES}

1. Leung DA, Hagspiel KD, Angle JF, et al. MR angiography of the renal arteries. Radiol Clin North Am 2002; 40:847-65.

2. Kawamoto S, Montgomery RA, Lawler LP, Horton $\mathrm{KM}$, Fishman EK. Multi-detector row CT evaluation of living renal donors prior to laparo scopic nephrectomy. Radiographics 2004; 24:45366.

3. El-Galley RES, Keane TE. Embryology, anatomy, and surgical applications of the kidney and ureter. Surg Clin North Am 2000; 80:381-401.

4. Kadir S. Angiography of the kidneys. In: Kadir S, ed. Diagnostic angiography. Philadelphia: Saunders, 1986; 445-95.

5. Rubin GD, Alfrey EJ, Dake MD, et al. Assessment of living renal donors with spiral CT. Radiology 1995; 195:457-62.

6. Mathews R, Smith PA, Fishman EK, Marshall FF. Anomalies of the inferior vena cava and renal veins: embryologic and surgical considerations. Urology 1999; 53:873-80.

7. Satheesha Nayak: Abnormal course of right renal artery and ovarian vessels: A Case Report. The Internet Journal of Biological Anthropology 2008; Volume 2 Number 1.

8. Pestemalci T, Mavi A, Yildiz YZ, Yildirim M, Gumusburun E. Bilateral triple renal arteries. Saudi J Kidney Dis Transpl 2009; 20:468-70.

9. Satyapal KS, Rambiritch V, Pillai GK. Morphometric analysis of the renal veins. Anat Rec 1995; 241:268-72.

10. Kapoor A, Lambe S, Kling AL, Piercey KR, Whelan PJ. Outcomes of laparoscopic donor nephrectomy in the presence of multiple renal arteries. Urol Ann 2011; 3:62-5. 